\title{
Hematological predictors of mortality in neonates with fulminant necrotizing enterocolitis
}

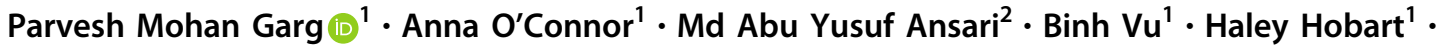 \\ Jaslyn L. Paschal $\mathbb{D}^{1} \cdot$ Harleen Multani ${ }^{1} \cdot$ Cassandra D. Josephson ${ }^{3} \cdot$ Victoria Okhomina ${ }^{2}$
}

Received: 2 October 2020 / Revised: 13 February 2021 / Accepted: 10 March 2021 / Published online: 26 March 2021

(c) The Author(s), under exclusive licence to Springer Nature America, Inc. 2021

\begin{abstract}
Objective Determine whether hematological and transfusion patterns following, the onset of NEC can identify infants likely to develop fulminant, fatal necrotizing enterocolitis (NEC).

Design Determine hematological predictors of fulminant NEC.

Results Of 336 neonates with NEC, 35 (10\%) who developed fulminant NEC were born with higher birth weights and more frequently developed radiologically evident pneumoperitoneumand/or portal venous gas. Following the diagnosis of NEC, these infants were more likely to rapidly develop thrombocytopenia, lymphopenia, neutropenia, and lower total white blood cell counts compared to medical/surgical non-fulminant type. They were also more likely to have received a red blood cell (RBC) transfusion $(76.7 \%$ vs. $53.1 \%, p=0.001)$ within $48 \mathrm{~h}$ after disease onset and platelet transfusion $(24.2 \%$ vs. $11.7 \%$; $p=0.03$ ) before the onset of NEC.

Conclusion Neonates with fulminant NEC frequently developed thrombocytopenia, lymphopenia, neutropenia, and leukopenia, received RBC transfusions after or platelet transfusions before the onset of NEC developed the fulminant disease.
\end{abstract}

\section{Introduction}

Necrotizing enterocolitis (NEC) is the most common acute gastrointestinal illness during the neonatal period, affecting about $5-10 \%$ of premature neonates with a birth weight $\leq 1500 \mathrm{~g}[1,2]$. Despite advances in neonatal intensive care, NEC remains a leading cause of surgical intervention, postoperative morbidity, and death in premature neonates [3-7]. A diagnosis of surgical NEC is associated with

Supplementary information The online version contains supplementary material available at https://doi.org/10.1038/s41372021-01044-3.

Parvesh Mohan Garg

gargparvesh@hotmail.com

1 Department of Pediatrics/Neonatology, University of Mississippi Medical Center, Jackson, MS, USA

2 Department of Data Science, University of Mississippi Medical Center, Jackson, MS, USA

3 Department of Pathology, Emory Center for Transfusion and Cellular Therapies, Emory University School of Medicine and Aflac Cancer and Blood Disorders Center, Children's Healthcare of Atlanta, Atlanta, GA, USA increased resource utilization and cost of care due to continued hospitalization that can last several months $[8,9]$. In these neonates, the disease is frequently marked by extensive bowel necrosis and inflammation [5, 10-13]. Some neonates develop what has been termed fulminant NEC and die within $48 \mathrm{~h}$ of diagnosis.

In the premature intestine, developmental limitations in both the innate and adaptive arms of the mucosal immune system increase the risk of inflammatory injury and NEC. Systemic inflammation during NEC has been associated with several hematological abnormalities [14] with altered counts of platelets, leukocytes including monocytes, neutrophils, and lymphocytes; and coagulopathy, and these changes may convey important diagnostic and prognostic information [15-18]. Platelet counts provide important predictive information for the outcome in these patients [19]. Neutropenia can be seen in severe NEC and is associated with adverse outcomes [14, 15, 17, 18]. In another study, Lambert et al. reported that neonates who died of fulminant NEC within $48 \mathrm{~h}$ of onset had low lymphocyte counts [20].

Neonates with NEC are frequently treated with blood product transfusions. Both clinical and animal model studies show anemia to change the intestinal inflammatory milieu 
and subsequent RBC transfusions to activate these newly recruited leukocytes in the intestinal wall and precipitate NEC [21-24]. Neonates with surgical NEC commonly receive platelet transfusions to treat severe thrombocytopenia [25], which can also accentuate the mucosal inflammation and may increase mortality [26-28].

Fulminant NEC is a severe subtype, categorized by panintestinal necrosis and death within $48 \mathrm{~h}$ of diagnosis. No studies have reported nadir hematological counts and recovery timeline after disease onset in neonates with medical/surgical NEC. Thus, it is difficult to forecast disease progression and outcome in the first $24 \mathrm{~h}$ after the NEC onset. In this context, it may be useful to understand whether the chronological evolution that we frequently see in routine laboratory results, such as hematological counts, has any prognostic implications. With the widespread availability of automated hematological analyzers, these data have now become relatively inexpensive and readily available and are comparable between centers. To address this knowledge gap, we aimed to determine the hematological and clinical predictors of mortality in infants with fulminant NEC. We also evaluated whether red blood cell transfusion and platelet transfusions before and/or during the $48 \mathrm{~h}$ following NEC onset were associated with mortality.

\section{Methods}

This retrospective study was conducted at the University of Mississippi Medical Center (UMMC) at Jackson, Mississippi, after approval by the Institutional Review Board (2017-0127). The protocol was considered compliant with the Health Insurance Portability and Accountability Act of 1996. The UMMC houses a level 4 neonatal intensive care unit, which is a regional referral center for neonates with surgical NEC in the entire state. A detailed review of the electronic medical records identified 336 patients with medical and surgical NEC (NEC Bell stage 2 and above) who underwent management of NEC in the period between January 2000 and December 2018. Infants who did not show obvious pneumatosis on radiology were classified as zstage 2 NEC only if they displayed highly suggestive definite clinical (intestinal) signs with loss of bowel sounds, tenderness, and abdominal distension; systemic instability with increased needs for ventilatory and hemodynamic support; and radiological signs such as intestinal dilatation, ascites, and/or portal venous gas.

\section{Definitions}

We defined fulminant NEC as a severe subtype, with death occurring within $48 \mathrm{~h}$ of onset, and with pan-intestinal necrosis shown at necropsy. Records of patients qualifying for fulminant NEC were compared with cases who developed surgical non-fulminant NEC (SNF) and with cases who developed medical non-fulminant NEC (MNF). Both of the latter group were alive $48 \mathrm{~h}$ after NEC onset. The infants with MNF either had confirmed pneumatosis on radiology exam or had all the clinical signs of NEC and were treated for at least 5-7 days of antibiotics.

\section{Clinical information}

We recorded demographic characteristics including birth weight, gestational age, gender, race (African-American, Caucasian, or Latino), and mode of delivery (C-section/ vaginal delivery), APGAR scores at $5 \mathrm{~min}$, outborn status, and small for gestational age status. We noted the NEC features such as the age of onset, pneumatosis, presence of $\mathrm{X}$ ray, and clinical presentation (abdominal distension, feeding intolerance, and bloody stools). We collected information regarding maternal factors, including pregnancy-induced hypertension, chorioamnionitis, and antenatal steroids. We collected information on clinical variables such as patent ductus arteriosus, PDA treatment medically or surgically, Creactive protein at 24 and $48 \mathrm{~h}$ after NEC onset cholestasis (direct bilirubin $>2 \mathrm{mg} / \mathrm{dL}$ ), blood cultures drawn at the time of NEC onset, use of inotropes at $24 \mathrm{~h}$, assisted ventilation, and antibiotic duration after NEC onset. We recorded information on the length of stay and mortality. The length of stay was defined as the number of days of hospitalization at the referring hospital and at UMMC. Mortality was defined as death due to any prior to hospital discharge.

\section{Hematological/transfusion information and time frame assessment}

We recorded complete blood cell count results from the electronic chart before the NEC onset (last available CBC inpatient record before NEC onset), on the day of NEC onset, $24 \mathrm{~h}$, and $48 \mathrm{~h}$ after onset. The pre-NEC CBC was mostly available 3-7 days before the NEC onset. We also recorded and compared complete blood count (CBC) results on days 4 and 7 for neonates with non-fulminant medical/surgical NEC. We collected data on relative (presented as percentages) as well as on the absolute values. If we had multiple $\mathrm{CBC}$ on the same day, we recorded data from what we judged to be the most abnormal one.

We also collected data on platelet and RBC transfusion before and after the NEC onset. In our hospital, decisions to order RBC or platelet transfusions are made by the on-call neonatologist. In our unit, blood transfusions are considered if the hematocrit is $\leq 30 \%$ (hemoglobin $\leq 10 \mathrm{gm} / \mathrm{dL}$ ) for neonates requiring moderate or significant mechanical 
(invasive/non-invasive) ventilation, defined as mean airway pressure $>8-\mathrm{cm} \mathrm{H}_{2} \mathrm{O}$ and $\mathrm{FiO}_{2}>0.40$ on a conventional ventilator. In our practice, all neonates are considered for transfusion of platelet count, which is $<30 \times 103 / \mathrm{cmm}$. Platelet transfusion is considered at counts $<50 \times 103 / \mathrm{cmm}$ if the neonate is $<1000 \mathrm{~g}$ ( $<7$ days old) and has $\mathrm{h} / \mathrm{o}$ previous intraventricular hemorrhage and pulmonary bleed. At our blood bank, regarding platelet transfusions of neonates, $\mathrm{AB}$ positive is the preferred type, but if unavailable, typespecific platelets are provided. Platelets expire within 5 days. Standard platelet preservation is ACD-A, stored constantly agitated at $20-24^{\circ} \mathrm{C}$. Platelet donations are collected from single apheresis donors. Neither platelets nor $\mathrm{RBCs}$ are washed, but both are irradiated in-house before transfusion for all neonates $<4$ months old.

\section{Statistical methods}

Patient demographics, and clinical and hematological information, were compared between the three NEC groups; MNF, SNF, and fulminant. Differences in continuous data were compared using the Kruskal-Wallis (Mann-Whitney $\mathrm{U})$ test and summarized with medians and interquartile ranges (Q3-Q1). Categorical variables were compared using Chi-squared tests and reported with frequencies and percentages. To estimate the associations between NEC status and hematological characteristics, multivariate logistic regression was used. Hematological characteristics that showed significant differences between NEC groups within $24 \mathrm{~h}$ after NEC onset were used in the logistic model with patient demographic information as covariates. Odds ratios and confidence intervals (CIs) (OR [95\% CI]) were reported to compare fulminant neonates to non-fulminant patients (reference group). All the statistical analyses were performed in $\mathrm{R}$ statistical software (version 3.6.3; The $\mathrm{R}$ Foundation for Statistical Computing). A $p$ value of $<0.05$ was considered significant.

\section{Results}

\section{Characteristics of the entire NEC cohort}

Three hundred and thirty-six neonates with NEC were studied in three cohorts: 35 (10.5\%) with fulminant NEC (death within $48 \mathrm{~h}$ of disease onset, and extensive bowel necrosis), 163 (48.5\%) with SNF, and 138 (41\%) with MNF NEC. In our entire cohort, the gestational age was mean \pm standard deviation $27.9 \pm 4$ weeks, and the birth weight was $1087 \pm 745 \mathrm{~g}$. The mean age of NEC onset was 21.2 days ( $\mathrm{SD} \pm 18.8$ days). Eighty-five $(26.5 \%)$ died. The data have been summarized in Table 1 .

\section{Comparison between fulminant and SNF}

Neonates with fulminant NEC had higher mean birth weight [917 g (IQR 708; 1158) vs.740 g (IQR 622; 990), $p=$ 0.036]. Those with fulminant NEC received significantly less exposure to antenatal steroids $(53.1 \%$ vs.SNF $65.2 \%$; $p=0.002$ ) and more likely to need ionotropic support at 24 $\mathrm{h}$ after NEC onset $(88.9 \%$ vs. SNF $67.8 \% ; p=0.04)$ compared to neonates with SNF NEC. Fewer had evidence of PDA on echocardiography ( $27.6 \%$ vs. SNF $58.8 \%$; $p=$ $0.004)$ and cholestasis (20\% vs. SNF $68.4 \%, p<0.001)$ neonates.

\section{Fulminant vs. MNF}

Neonates with fulminant NEC were more likely to have pneumatosis $(52.4 \%$ vs. $42.2 \%)$, portal venous gas $(18.8 \%$ vs. $1.8 \%, p=0.001)$, and pneumoperitoneum $(31.2 \%$ vs. MNF $4.5 \% ; p<0.001)$ on abdominal radiographs. A larger proportion of those with fulminant NEC received inotropes $(88.9 \%$ vs. $20.4 \%$ in MNF, $p \leq 0.001$ ) and assisted ventilation (92\% vs. MNF $41.8 \%, p<0.001)$. $\mathrm{C}$-reactive protein levels were significantly higher at NEC onset, and 2 days, later in those with fulminant NEC $(p \leq 0.001$ vs. MNF).

In the fulminant NEC group, 20/35 infants were alive at $24 \mathrm{~h}$ after NEC onset, and only eight infants were alive at $36 \mathrm{~h}$ of NEC onset. The Kaplan-Meier curve depicting the trend of mortality in neonates with fulminant NEC has been summarized in Fig. 1. All neonates with fulminant NEC died while 40 (24.7\%) with SNF and $10(8.0 \%)$ in the MNF group died $(<0.001)$, all beyond $48 \mathrm{~h}$ (Table 1$)$.

\section{Blood transfusions}

One hundred and forty-one (47\%) infants had received RBC transfusion from birth until the NEC onset. The three groups did not differ in the number of RBC transfusions received before the onset of NEC. Infants who developed fulminant NEC (77.4\%) and SNF NEC (77.4\%) were more likely to have received RBC transfusions in the 48 -h period following the onset of NEC than those with MNF (30.1\%; $p<$ 0.001). These data are shown in Table 2.

Thirty-four (15\%) patients had received platelet transfusions from birth until the onset of NEC. The three groups did not differ in the number of platelet transfusions prior to the onset of NEC. Seventy-seven (34\%) of these neonates had received platelet transfusions in the $48 \mathrm{~h}$ following the onset of NEC. Those with fulminant (42.1\%) and SNF NEC $(41.6 \%)$ were more likely to have received platelet transfusions within $48 \mathrm{~h}$ after developing NEC than those with MNF NEC $(9.4 \% ; p<0.001)$. 


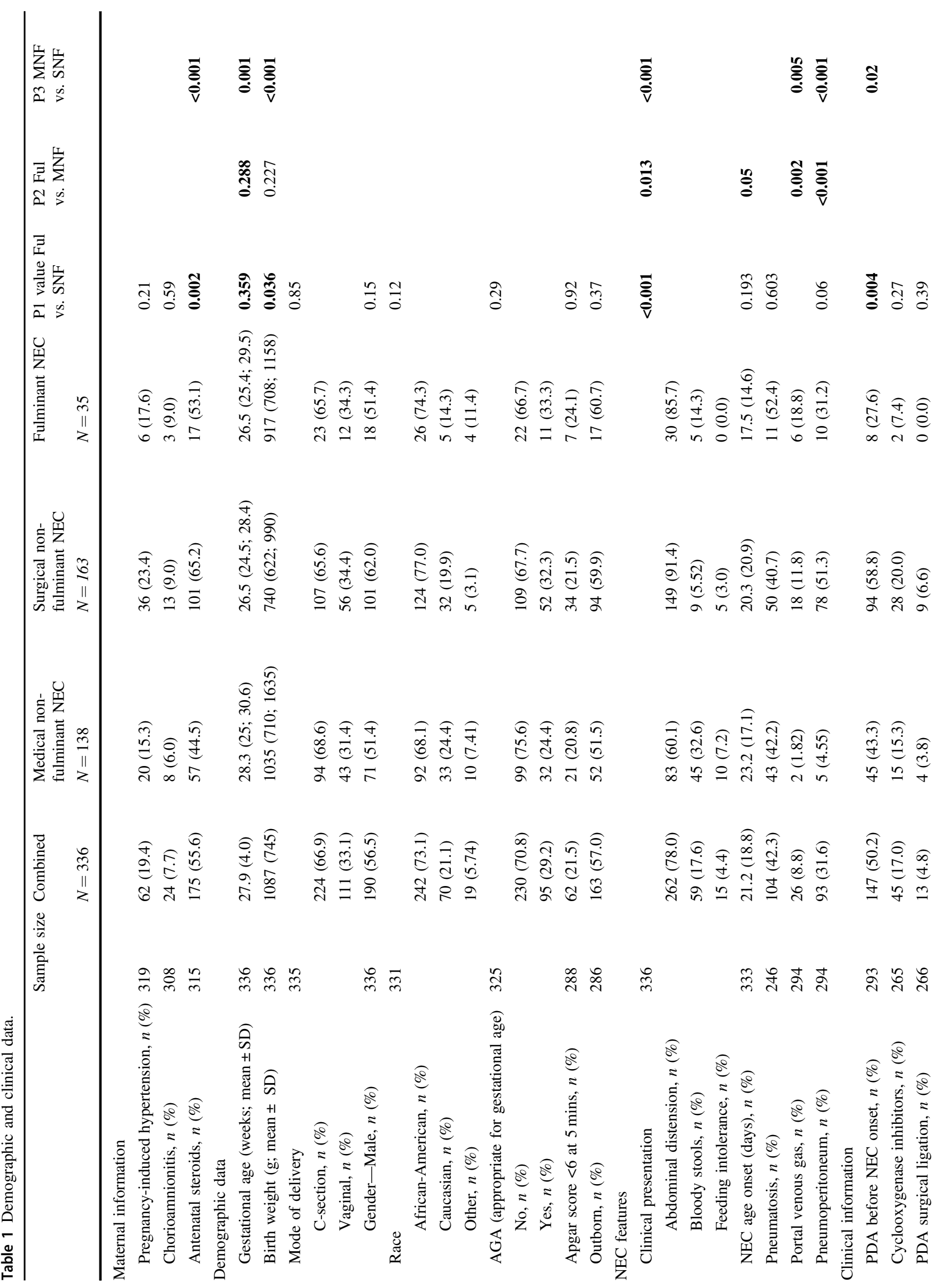




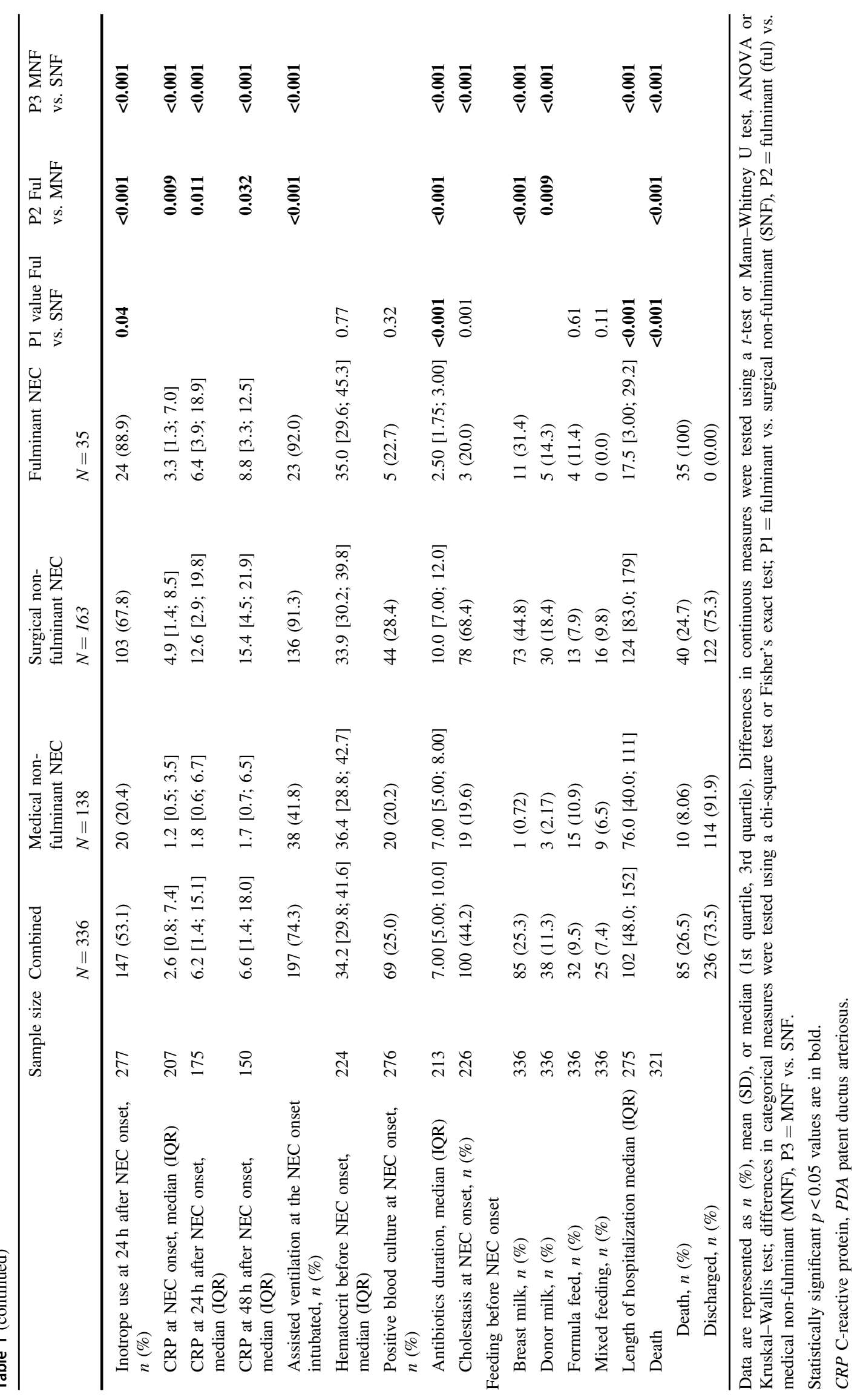



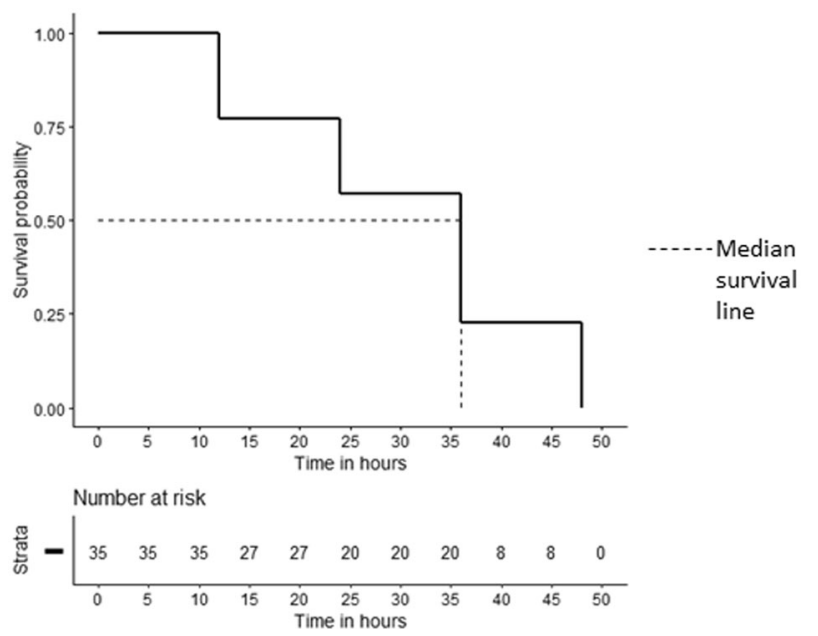

Survival Curve for infants with fulminant NEC

Fig. 1 Kaplan-Meier curve (survival curve) showing mortality in neonates with fulminant necrotizing enterocolitis. The dotted line represents the median survival line. $X$-axis represents the time in $\mathrm{h}$. The numerical 0 on the $X$-axis represents the time of NEC onset. $Y$-axis represents the survival probablity.

\section{First $48 \mathrm{~h}$ after NEC}

Patients with fulminant NEC on the day of NEC onset were more likely to have had lower absolute lymphocyte count [3.96 (IQR 2, 64; 6.04) fulminant NEC vs. 4.59 (IQR 1.00; 5.25) SNF; $p=0.017]$, lower median platelet count [134 (IQR 91.8; 193) in fulminant group vs. 230 (IQR 143; 331) in MNF; $p \leq 0.001]$. At $24 \mathrm{~h}$ after NEC onset, neonates with fulminant NEC had significantly lower lymphocyte count [3.78 (IQR 2.70; 5.08) fulminant NEC vs. 4.23 (IQR 3.00; 6.00) SNF; $p=0.021$ ], lower platelet count [82 (IQR 61.8; 110) in fulminant group vs. 208 (IQR 133; 276) in MNF; $p \leq 0.001]$ as compared to the surgical and MNF group. At $48 \mathrm{~h}$ after NEC onset, neonates with fulminant NEC had significantly lower median platelet count [73 (IQR 41; 166) in fulminant group vs. 208 (IQR 134; 280) in MNF; $p=$ 0.015], lower total white blood cell count [9.3 (IQR 4.4; 10.3) vs. 11.4 (IQR 9.15; 18.4) MNF, p=0.04), lower absolute neutrophil count $[2.96$ (IQR $1.52 ; 3.16$ ) fulminant NEC vs. 4.48 (IQR 2.82; 8.96) MNF; $p=0.039$ ] and significantly lower absolute lymphocyte count [1.86 [IQR 1.21; 3.12] fulminant NEC group vs. 4.70 [IQR 3.44; 5.88] in MNF; $p=0.001]$ as compared to neonates with MNF group. Blood count profiles are shown in detail in Supplementary Table 1 and Fig. 2.

\section{Relative blood values}

On the day of NEC onset, those neonates with fulminant NEC had lower neutrophil percentages (26\% vs. MNF $42 \%$, $p<0.009$; vs. SNF $41 \%, p=0.016$ ), and, however, the monocyte percentages were significantly higher in neonates with SNF NEC group [14.0 (IQR 10.0; 21.0) fulminant group vs. 11.0 (IQR 7.00; 16.8) in MNF; $p=0.03$ ] as compared to the MNF group on the day of NEC onset. The data are shown in Supplementary Table 1 and Figs. 1, 2.

\section{Blood profile, SNF, and MNF, days 3-7}

Those with SNF NEC had lower platelet and lymphocyte counts than did those with MNF NEC, from the day of onset until day $7(p<0.001)$. In both groups, the fall in platelets continued until day $4(p<0.001)$ with recovery by day 7 . Those with SNF NEC had higher monocyte percentages and absolute monocyte counts on days 3 ( $p=$ $0.02), 4(p=0.03)$, and $7(p=0.04)$. The eosinophil counts did not differ between the two groups, except on day $7(p=0.04)$.

Using unadjusted modeling, a difference in absolute neutrophil count $(p=0.04)$ and platelet count $(p=0.01)$ between pre-NEC values and those found at NEC onset was associated with increased odds of fulminant NEC (or death). Also, the platelet count at $24 \mathrm{~h}$ after NEC onset was associated with increased odds of fulminant NEC $(p=0.03)$. The absolute neutrophil count and WBC count at $48 \mathrm{~h}$ were associated with increased odds of fulminant NEC (or death). We found similar trends at different time assessment points after adjusting the predictive model for gestational age and birth weight. That data are summarized in Table 3. On predictive modeling, for a $5 \%$ increase in neutrophils on the day of NEC diagnosis relative to pre-NEC neutrophil percentages, the odds of fulminant NEC decreased by $16 \%$ [OR 0.84 (95\% CI; 0.74, 0.94); $p=0.002$ ] after adjusting for birth weight, gestational age, and clinical presentation of abdominal distention. The model did not reveal other relationships with blood values. That data are summarized in Table 4. We also analyzed the interplay of different blood component counts at different time points after NEC onset with each other by interaction predictive modeling, as shown in Supplementary Table 2. The interactive model did not find any significant interaction except for absolute lymphocyte count and platelet count on the day of NEC onset $(p=0.006)$.

\section{Transfusion number and mortality}

The neonates who died were more likely to have received a platelet transfusion before NEC onset $(24.2 \%$ vs. $11.7 \%$; $p=0.03$ ). However, platelet transfusions during the $48 \mathrm{~h}$ after NEC onset did not discriminate between non-survivors vs. survivors $(p=0.98)$. RBC transfusions were not more likely before NEC onset among non-survivors than survivors $(52.4 \%$ vs. $46.1 \% ; p=0.48)$. However, RBC 
Table 2 Transfusion frequency in three subtypes of necrotizing enterocolitis.

\begin{tabular}{|c|c|c|c|c|c|c|c|}
\hline & $\begin{array}{l}\text { Combined } \\
\text { cohort }(N=336)\end{array}$ & $\begin{array}{l}\text { Medical non- } \\
\text { fulminant NEC } \\
(N=138)\end{array}$ & $\begin{array}{l}\text { Surgical non- } \\
\text { fulminant NEC } \\
(N=163)\end{array}$ & $\begin{array}{l}\text { Fulminant NEC } \\
(N=35)\end{array}$ & $\begin{array}{l}\text { P1 Ful } \\
\text { vs. SNF }\end{array}$ & $\begin{array}{l}\text { P2 Ful } \\
\text { vs. MNF }\end{array}$ & $\begin{array}{l}\text { P3 SNF } \\
\text { vs. MNF }\end{array}$ \\
\hline $\begin{array}{l}\text { Platelet transfusion } \\
\text { before NEC }\end{array}$ & $n=226$ & $n=56$ & $n=152$ & $n=18$ & & & \\
\hline $\begin{array}{l}\text { Number of platelet } \\
\text { transfusion, } n(\%)\end{array}$ & & & & & 0.319 & 0.337 & 0.892 \\
\hline 0 & $192(85.0 \%)$ & $48(85.7 \%)$ & $130(85.5 \%)$ & $14(77.8 \%)$ & & & \\
\hline 1 & $17(7.52 \%)$ & $5(8.93 \%)$ & $11(7.24 \%)$ & $1(5.56 \%)$ & & & \\
\hline 2 & $8(3.54 \%)$ & $1(1.79 \%)$ & $6(3.95 \%)$ & $1(5.56 \%)$ & & & \\
\hline $3+$ & $9(3.98 \%)$ & $2(3.57 \%)$ & $5(3.29 \%)$ & $2(11.1 \%)$ & & & \\
\hline $\begin{array}{l}\text { Platelet transfusion } \\
\text { after } 48 \mathrm{~h}\end{array}$ & $n=226$ & $n=53$ & $n=154$ & $n=19$ & & & \\
\hline $\begin{array}{l}\text { Number of platelet } \\
\text { transfusion, } n(\%)\end{array}$ & & & & & 0.373 & 0.002 & $<0.001$ \\
\hline 0 & $149(65.9 \%)$ & $48(90.6 \%)$ & $90(58.4 \%)$ & $11(57.9 \%)$ & & & \\
\hline 1 & $46(20.4 \%)$ & $3(5.66 \%)$ & $36(23.4 \%)$ & $7(36.8 \%)$ & & & \\
\hline 2 & $17(7.52 \%)$ & $1(1.89 \%)$ & $16(10.4 \%)$ & $0(0.00 \%)$ & & & \\
\hline $3+$ & $14(6.19 \%)$ & $1(1.89 \%)$ & $12(7.79 \%)$ & $1(5.26 \%)$ & & & \\
\hline $\begin{array}{l}\text { RBC transfusion } \\
\text { before NEC }\end{array}$ & $n=296$ & $n=122$ & $n=143$ & $n=31$ & & & \\
\hline $\begin{array}{l}\text { Number of RBC } \\
\text { transfusion, } n(\%)\end{array}$ & & & & & 0.392 & 0.335 & 0.246 \\
\hline 0 & $155(52.4 \%)$ & $67(54.9 \%)$ & $71(49.7 \%)$ & $17(54.8 \%)$ & & & \\
\hline 1 & $29(9.80 \%)$ & $12(9.84 \%)$ & $12(8.39 \%)$ & $5(16.1 \%)$ & & & \\
\hline 2 & $35(11.8 \%)$ & $9(7.38 \%)$ & $22(15.4 \%)$ & $4(12.9 \%)$ & & & \\
\hline $3+$ & $77(26.0 \%)$ & $34(27.9 \%)$ & $38(26.6 \%)$ & $5(16.1 \%)$ & & & \\
\hline $\begin{array}{l}\text { RBC transfusion after } \\
48 \mathrm{~h} \mathrm{NEC}\end{array}$ & $n=281$ & $n=113$ & $n=137$ & $n=31$ & & & \\
\hline $\begin{array}{l}\text { Number of RBC } \\
\text { transfusion, } n(\%)\end{array}$ & & & & & 0.574 & $<0.001$ & $<0.001$ \\
\hline 0 & $117(41.6 \%)$ & $79(69.9 \%)$ & $31(22.6 \%)$ & $7(22.6 \%)$ & & & \\
\hline 1 & $91(32.4 \%)$ & $29(25.7 \%)$ & $48(35.0 \%)$ & $14(45.2 \%)$ & & & \\
\hline 2 & $40(14.2 \%)$ & $4(3.54 \%)$ & $32(23.4 \%)$ & $4(12.9 \%)$ & & & \\
\hline $3+$ & $33(11.7 \%)$ & $1(0.88 \%)$ & $26(19.0 \%)$ & $6(19.4 \%)$ & & & \\
\hline
\end{tabular}

Data represented as $n(\%)$; differences in categorical measures tested using the Chi-squared test or Fisher's exact test; P1 = Fulminant vs. surgical non-fulminant (SNF), $\mathrm{P} 2=$ fulminant (ful) vs. medical non-fulminant (MNF), $\mathrm{P} 3=\mathrm{MNF}$ vs. SNF, $p<0.05$ significant.

Statistically significant $p<0.05$ values are in bold.

$N E C$ necrotizing enterocolitis, $R B C$ red blood cell.

transfusion in the $48 \mathrm{~h}$ after NEC onset was more likely in non-survivors $(76.7 \%$ vs. $53.1 \%, p=0.001)$. This data is given in Table 5.

\section{Discussion}

Our data demonstrate that neonates who develop fulminant NEC have a different hematological profile than those with non-fulminant medical or surgical disease. In the $48 \mathrm{~h}$ following diagnosis, infants with fulminant NEC had lower total leukocyte counts, and the absolute counts of neutrophils, lymphocytes, and eosinophils, but higher monocyte counts. The platelet counts were lower. Clinically, the fulminant disease occurred at an earlier postnatal age. As anticipated, the fulminant disease course was associated with more extensive clinical disease seen with prominent radiological signs such as portal venous gas prior to surgery and greater needs for assisted ventilation and inotropes before and after surgery. In infants with the nonfulminant disease, the clinical features were closer to our anticipations. Compared to MNF NEC, infants with surgical 
a.

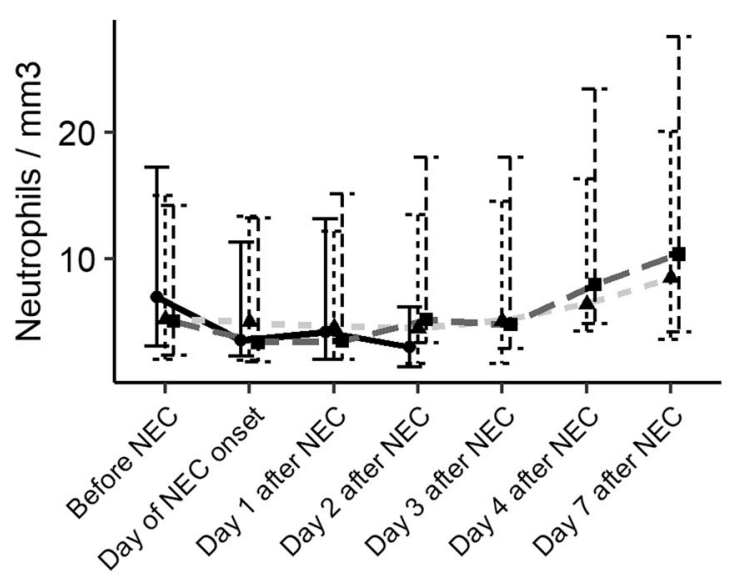

C.

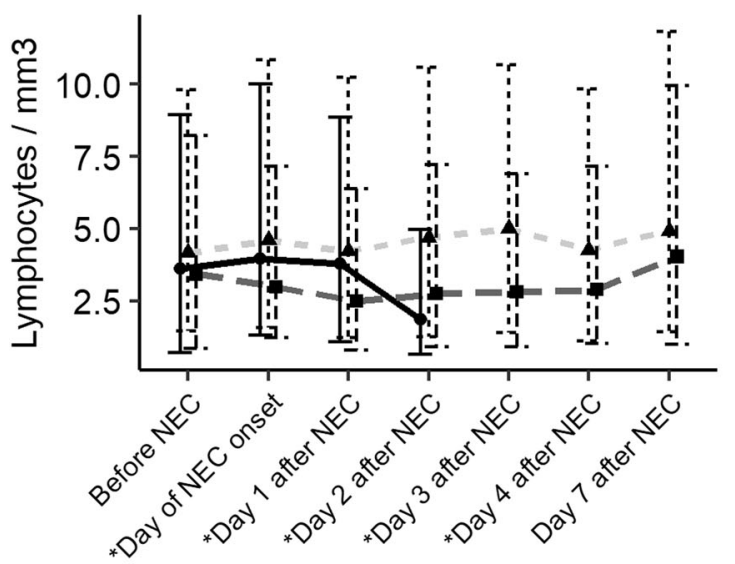

b.

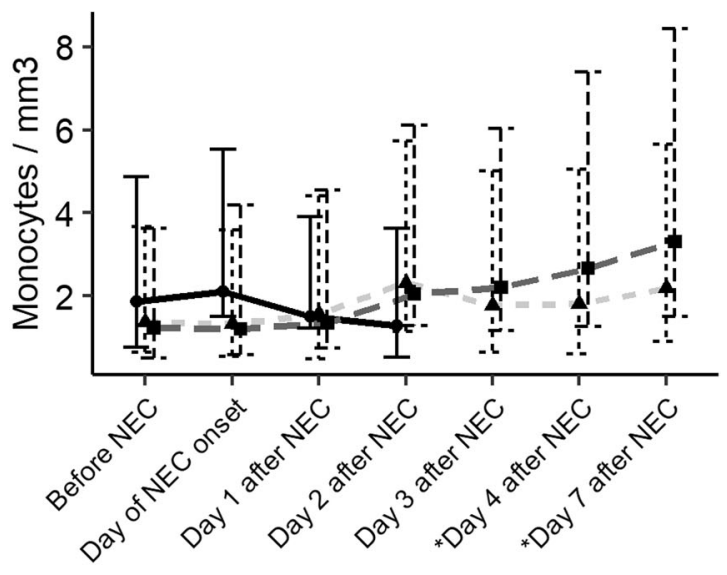

d.

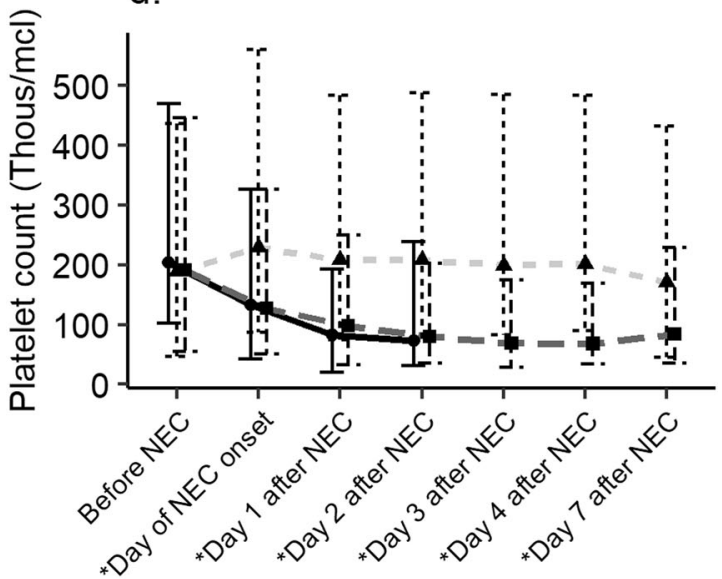

Fulminant NEC - Medical Non-Fulminant NEC

Surgical Non-Fulminant NEC

Fig. 2 Heamatological changes before and seven days after NEC onset. Absolute blood values of neutrophils (a), monocytes (b), lymphocytes (c), platelet count (d) in three different subtypes of NEC. The circle, triangle, and sqaure symbol represent neonates with

but non-fulminant NEC had lower gestation age and birth weights and had a higher severity of illness related to prematurity with a higher frequency of PDA and need for assisted ventilation. As anticipated, those who needed surgery had higher CRP levels and more frequently documented pneumoperitoneum.

The incidence of fulminant NEC in our study $(10 \%)$ was lower than in the study by Lin et al. [29], who reported 352 neonates, 112 of whom $(31.8 \%)$ met the fulminant NEC criteria. They had, on average, a higher gestational age (37.0 weeks) and birth weight $(2610 \mathrm{~g})$ than ours (mean GA $27.9 \pm 4.0$ weeks and mean birth weight $1087 \pm 745$ ) and showed different hematological findings. They had lower leukocyte and neutrophil counts but no differences in fulminant, medical non-fulminant, and surgical non-fulminant NEC. The data have been depicted as a median (IQR). The asterisk * on the $x$-axis represents $p<0.05$.

platelet count, compared with non-fulminant cases. In another study, Lambert et al. reported fulminant NEC in $6.7 \%$ of 523 cases, which was less than in our study [20]. The gestational age and birth weight of neonates with fulminant NEC resembled our cohort, at $27.5 \pm 2.4$ weeks and $1089 \pm 545 \mathrm{~g}$. They reported a higher rate of portal venous gas in fulminant cases $(N=20 / 35,57 \%)$.

Several previous studies $[14,15,17,18]$ have reported thrombocytopenia in surgical NEC. However, only a few commented on their nadir and none on the recovery timeline (trend toward pre-NEC levels). We found significant thrombocytopenia in fulminant and non-fulminant NEC $(73.0$ [41.8; 166] and 68.0 [33.8; 101] SNF) lasting 48 and $96 \mathrm{~h}$, respectively, and noticed recovery generally 
Table 3 Association between fulminant NEC and hematological measures using multinomial logistic regression.

\begin{tabular}{|c|c|c|c|c|c|c|c|c|c|c|}
\hline \multirow[b]{2}{*}{ Difference } & \multicolumn{5}{|c|}{ Unadjusted models } & \multicolumn{5}{|c|}{ Adjusted models } \\
\hline & $\beta$ & OR & $p$ value & $95 \% \mathrm{CI}$ & & $\beta$ & OR & $p$ value & $95 \% \mathrm{C}$ & \\
\hline \multicolumn{11}{|l|}{$\Delta$ Absolute neutrophil count } \\
\hline$\Delta$ ANC before and day of NEC & 0.07 & 1.07 & 0.04 & 1.003 & 1.14 & 0.07 & 1.07 & 0.04 & 1.003 & 1.14 \\
\hline$\Delta \mathrm{ANC}$ before and $24 \mathrm{~h} \mathrm{NEC}$ & 0.05 & 1.05 & 0.29 & 0.96 & 1.15 & 0.05 & 1.05 & 0.27 & 0.96 & 1.15 \\
\hline$\Delta \mathrm{ANC}$ before and $48 \mathrm{~h}$ NEC & 0.08 & 1.09 & 0.09 & 0.99 & 1.20 & 0.10 & 1.10 & 0.07 & 0.99 & 1.22 \\
\hline \multicolumn{11}{|l|}{ Absolute lymphocyte count } \\
\hline$\Delta$ ALC before and day of NEC & -0.03 & 0.97 & 0.73 & 0.81 & 1.16 & -0.04 & 0.96 & 0.68 & 0.80 & 1.16 \\
\hline$\Delta \mathrm{ALC}$ before and $24 \mathrm{~h} \mathrm{NEC}$ & 0.14 & 1.15 & 0.29 & 0.89 & 1.47 & 0.14 & 1.15 & 0.29 & 0.89 & 1.48 \\
\hline$\Delta$ ANC before and $48 \mathrm{~h}$ NEC & 0.24 & 1.27 & 0.19 & 0.89 & 1.82 & 0.25 & 1.29 & 0.18 & 0.89 & 1.86 \\
\hline \multicolumn{11}{|l|}{ Platelet count } \\
\hline$\Delta$ Platelet before and day of NEC & 0.01 & 1.01 & 0.01 & 1.001 & 1.01 & 0.004 & 1.00 & 0.02 & 1.001 & 1.01 \\
\hline$\Delta$ Platelet before and $24 \mathrm{~h} \mathrm{NEC}$ & 0.01 & 1.01 & 0.03 & 1.001 & 1.01 & 0.01 & 1.01 & 0.05 & 1.000 & 1.01 \\
\hline$\Delta$ Platelet before and $48 \mathrm{~h} \mathrm{NEC}$ & 0.01 & 1.01 & 0.11 & 1.00 & 1.01 & 0.01 & 1.01 & 0.14 & 0.99 & 1.01 \\
\hline \multicolumn{11}{|l|}{ Absolute monocytes count } \\
\hline$\Delta$ AMC before and day of NEC & 0.17 & 1.18 & 0.2 & 0.92 & 1.52 & 0.18 & 1.19 & 0.17 & 0.93 & 1.53 \\
\hline$\Delta \mathrm{AMC}$ before and $24 \mathrm{~h} \mathrm{NEC}$ & 0.12 & 1.12 & 0.46 & 0.82 & 1.53 & 0.13 & 1.14 & 0.43 & 0.83 & 1.57 \\
\hline$\Delta \mathrm{AMC}$ before and $48 \mathrm{~h} \mathrm{NEC}$ & 0.24 & 1.27 & 0.22 & 0.87 & 1.84 & 0.26 & 1.29 & 0.20 & 0.87 & 1.91 \\
\hline \multicolumn{11}{|l|}{ WBC count } \\
\hline$\Delta$ WBC before and day of NEC & 0.03 & 1.03 & 0.13 & 0.99 & 1.08 & 0.03 & 1.03 & 0.14 & 0.99 & 1.08 \\
\hline$\Delta \mathrm{WBC}$ before and $24 \mathrm{~h} \mathrm{NEC}$ & 0.05 & 1.05 & 0.12 & 0.99 & 1.11 & 0.05 & 1.05 & 0.09 & 0.99 & 1.12 \\
\hline$\Delta \mathrm{WBC}$ before and $48 \mathrm{~h} \mathrm{NEC}$ & 0.06 & 1.06 & 0.04 & 1.003 & 1.12 & 0.06 & 1.07 & 0.03 & 1.01 & 1.13 \\
\hline \multicolumn{11}{|l|}{ Eosinophil count } \\
\hline$\Delta$ AEC before and day of NEC & -0.002 & 1.00 & 0.98 & 0.86 & 1.16 & -0.02 & 0.99 & 0.85 & 0.84 & 1.16 \\
\hline$\Delta \mathrm{AEC}$ before and $24 \mathrm{~h} \mathrm{NEC}$ & -0.02 & 0.98 & 0.77 & 0.84 & 1.14 & -0.03 & 0.98 & 0.74 & 0.84 & 1.13 \\
\hline$\Delta$ AEC before and $48 \mathrm{~h}$ NEC & -0.08 & 0.93 & 0.35 & 0.79 & 1.08 & -0.07 & 0.93 & 0.40 & 0.80 & 1.10 \\
\hline \multicolumn{11}{|l|}{ Monocytes $(\%)$} \\
\hline$\Delta \%$ Monocyte before and day of NEC & 0.02 & 1.02 & 0.48 & 0.96 & 1.08 & 0.02 & 1.02 & 0.48 & 0.96 & 1.08 \\
\hline$\Delta \%$ Monocyte before and $24 \mathrm{~h} \mathrm{NEC}$ & -0.01 & 0.99 & 0.69 & 0.93 & 1.05 & -0.01 & 0.99 & 0.71 & 0.93 & 1.05 \\
\hline$\Delta \%$ Monocyte before and $48 \mathrm{~h} \mathrm{NEC}$ & -0.04 & 0.96 & 0.27 & 0.89 & 1.03 & -0.05 & 0.96 & 0.25 & 0.88 & 1.03 \\
\hline \multicolumn{11}{|l|}{ Neutrophil (\%) } \\
\hline$\Delta \%$ Neutrophil before and day of NEC & 0.03 & 1.03 & 0.02 & 1.004 & 1.05 & 0.03 & 1.03 & 0.02 & 1.003 & 1.05 \\
\hline$\Delta \%$ Neutrophil before and $24 \mathrm{~h}$ NEC & 0.02 & 1.02 & 0.17 & 0.99 & 1.05 & 0.02 & 1.02 & 0.18 & 0.99 & 1.05 \\
\hline$\Delta \%$ Neutrophil before and $48 \mathrm{~h} \mathrm{NEC}$ & 0.04 & 1.04 & 0.04 & 1.002 & 1.08 & 0.04 & 1.04 & 0.05 & 1.00 & 1.08 \\
\hline \multicolumn{11}{|l|}{ Lymphocyte (\%) } \\
\hline$\Delta \%$ Lymphocyte before and day of NEC & -0.02 & 0.98 & 0.20 & 0.96 & 1.008 & -0.02 & 0.98 & 0.20 & 0.96 & 1.01 \\
\hline$\Delta \%$ Lymphocyte before and $24 \mathrm{~h} \mathrm{NEC}$ & 0.001 & 1.001 & 0.95 & 0.97 & 1.04 & 0.001 & 1.00 & 0.99 & 0.97 & 1.04 \\
\hline$\Delta \%$ Lymphocyte before and $48 \mathrm{~h} \mathrm{NEC}$ & 0.002 & 1.002 & 0.94 & 0.95 & 1.05 & 0.003 & 1.00 & 0.90 & 0.96 & 1.05 \\
\hline
\end{tabular}

Adjusted models: models are adjusted for gestational age and birth weight; all values reported as OR (95\% CI); ref: medical non-fulminant NEC; $p$ value compares fulminant NEC and medical non-fulminant group. 48-h time point represents the data from alive infants between 24 and $48 \mathrm{~h}$. Statistically significant $p<0.05$ values are in bold.

$O R$ odds ratio, $C I$ confidence interval.

after 4 days in the survivors. Our patients with fulminant NEC (all of whom died within $48 \mathrm{~h}$, by definition) had the lowest platelet counts at $73 \mathrm{TH} / \mathrm{cmm}[41.8 ; 166]$ than 80 $\mathrm{TH} / \mathrm{cmm}$ [45.0; 123] SNF and $208 \mathrm{TH} / \mathrm{cmm} \mathrm{[134;} \mathrm{280]}$ MNF, which resembled the observations in other studies $[15,19]$. The exact mechanism causing thrombocytopenia in these NEC is still uncertain, but consumptive disorders are likely and include the formation of microthrombi in the diseased intestine [30] and platelet activation from bacterial products leading to aggregation in the microvasculature [31].
A recent mouse study reported thrombin-mediated platelet activation [32, 33]. Few human studies have reported decreased immature platelet fraction and increased mean platelet volume in neonates with NEC [34, 35]. In our study, we did not find significant differences in mean platelet volume in three groups.

Our findings suggest that neonates with surgical fulminant and the non-fulminant group had significantly lower absolute neutrophil counts from the day of NEC until $48 \mathrm{~h}$ after onset, and recovery was noticed on day 3 in those with surgical NEC. Other investigators reported neutropenia in 
Table 4 Associations between fulminant NEC and blood profile.

\begin{tabular}{llc}
\hline Model & OR $(95 \%$ CI $)$ & $p$ value \\
\hline Day of NEC & & \\
$\quad$ White blood cells $(\%)^{\mathrm{a}}$ & $0.94(0.81,1.09)$ & 0.42 \\
${\text { Neutrophils }(\%)^{\mathrm{a}}}^{\text {Absolute lymphocytes count }}$ & $0.84(0.74,0.94)$ & $\mathbf{0 . 0 0 2}$ \\
Lymphocytes $(\%)^{\mathrm{a}}$ & $0.98(0.85,1.14)$ & 0.8 \\
Mean platelet volume & $0.75(0.54,1.04)$ & 0.09 \\
Platelet count & $0.99(0.989,0.99)$ & 0.02 \\
24 h after NEC & & \\
Neutrophils $(\%)^{\mathrm{a}}$ & $0.96(0.84,1.08)$ & 0.48 \\
Absolute lymphocytes & $0.96(0.82,1.13)$ & 0.64 \\
Lymphocytes $(\%)^{\mathrm{a}}$ & $0.93(0.80,1.08)$ & 0.32 \\
Platelet count & $0.98(0.98,0.99)$ & $<\mathbf{0 . 0 0 1}$ \\
\hline
\end{tabular}

All values reported as OR (95\% CI). Each model was adjusted for birth weight, gestational age.

Statistically significant $p<0.05$ values are in bold.

$O R$ odds ratio, $C I$ confidence interval.

a5\% change.

neonates with fulminant NEC; however, those studies did not report serial timing of neutropenia in relation to NEC onset $[15,29]$. Defining the timeline might give an opportunity for early diagnostic and therapeutic inventions. Hutter et al. studied the bone marrow of neonates who died due to NEC and reported normal granulocyte precursors [15]. Our predictive model suggests that improvement in the neutrophil count by every $5 \%$ is associated with decreased risk of fulminant NEC.

Lambert et al. reported lower lymphocyte counts $[(<4000 / \mu \mathrm{l})(p=0.018)]$ in neonates with fulminant NEC [20]. Our findings also suggest significant lymphopenia in neonates with fulminant NEC from the day of NEC onset until day 2 and until day 7 in neonates with SNF NEC. The data indicate a longer-lasting duration of lymphopenia/or delayed recovery as compared to neutropenia in neonates with SNF NEC. We also observed significantly lower eosinophil count in neonates with fulminant and nonfulminant NEC. This needs further investigation to understand the role of eosinophils in fulminant NEC. We observed a variable pattern of monocytes. The neonates with SNF NEC had lower absolute monocyte counts as compared to those with medical NEC until $48 \mathrm{~h}$ after NEC onset, and the significant opposite pattern was [36] seen on days 4 and 7. This may be explained due to tissue/intestinal infiltration with monocytes in the NEC condition, as shown in animal models $[37,38]$. The increase in monocyte counts noted from day 4 onwards most probably reflects mobilization, an attempt at recovery.

In our study, the non-survivors received significantly more platelet transfusions before NEC onset. A recently published randomized trial by Carley et al. demonstrated that neonates who receive platelet transfusions at a platelet-count threshold of 50,000 per cubic millimeter had a significantly higher rate of death or major bleeding within 28 days after randomization than those who received platelet transfusions at a platelet-count threshold of 25,000 per cubic millimeter [28]. A previously published study by Kenton et al. did not find an effect of platelet transfusion on mortality. However, they reported an increased frequency of morbidities, such as short bowel syndrome and cholestasis [27]. In a recent report [26], which studied 598 very-low-birth-weight neonates, 44 developed NEC. In unadjusted analysis, platelet transfusion rate was 30.3 (95\% CI, 11.5-80.1) per 100 infant-days among neonates who died, compared to $6.0(95 \% \mathrm{CI}$, 3.2-11.2) among survivors (incidence rate ratio, 5.1; 95\% CI, $1.6-16.2 ; p=0.006)$. The contribution of platelet transfusions to mortality may be explained due to increased levels of pro-inflammatory mediators such as neuropeptide $\mathrm{Y}$ in the stored platelets [26].

In our study, the rate of blood transfusion from birth until the NEC onset did not affect mortality. A recent study by Wang et al. reported associations between the number of RBC transfusions and in-hospital mortality and morbidity. The number of RBC transfusions within 7 days of birth was not different among those who went on to develop NEC $(3.0 \pm 2.6)$ vs. those who did not develop NEC $(2.8 \pm 1.7, p$ $=0.521$ ) [39]. Similarly, in our previous meta-analysis, we did not find an association between RBC transfusion and NEC onset [23]. In the present study, the non-survivors were more likely to receive an RBC transfusion within $48 \mathrm{~h}$ after NEC onset.

Our study's strengths include our evaluation of nadir and recovery of different hematological variables, perhaps providing insights about disease pathophysiology and direction for further research. Our data validate the observation that platelet transfusion before NEC onset was associated with adverse outcomes. We acknowledge study limitations, including the single-center retrospective design and the relatively small sample size of infants with fulminant NEC.

In conclusion, neonates with medical, surgical, and fulminant NEC have somewhat different clinical and hematological patterns after the NEC onset. The fulminant NEC neonates were more likely to be associated with lower platelet count and lower total white blood cell count, lower neutrophil count, and lower lymphocyte count after the NEC onset. In addition, the higher frequency of platelet transfusions before NEC onset was associated with an increased risk of fulminant NEC. In the future, larger, prospective multicenter studies that include additional clinical detail (e.g., mesenteric perfusion using NIRS) and laboratory predictors such as hematological and stool biomarkers may inform earlier recognition of or risk factors for fulminant NEC. 
Table 5 Transfusion and mortality.

\begin{tabular}{|c|c|c|c|c|c|c|c|c|}
\hline & \multirow{2}{*}{$\begin{array}{l}\text { ALL } \\
N=321\end{array}$} & \multicolumn{3}{|c|}{ Combined group } & \multicolumn{4}{|l|}{ Discharged } \\
\hline & & $\begin{array}{l}\text { Death } \\
N=85\end{array}$ & $\begin{array}{l}\text { Discharged } \\
N=236\end{array}$ & $p$ value & $\begin{array}{l}\text { ALL } \\
N=236\end{array}$ & $\begin{array}{l}\text { MNF NEC } \\
N=114\end{array}$ & $\begin{array}{l}\text { SNF NEC } \\
N=122\end{array}$ & $p$ value \\
\hline Platelet tx before NEC & $n=225$ & $n=62$ & $n=163$ & & $n=163$ & $n=51$ & $n=112$ & \\
\hline Platelet tx before NEC & & & & 0.09 & & & & 0.832 \\
\hline 0 & $191(84.9 \%)$ & $47(75.8 \%)$ & $144(88.3 \%)$ & & $144(88.3 \%)$ & $44(86.3 \%)$ & $100(89.3 \%)$ & \\
\hline 1 & $17(7.56 \%)$ & $7(11.3 \%)$ & $10(6.13 \%)$ & & $10(6.13 \%)$ & $4(7.84 \%)$ & $6(5.36 \%)$ & \\
\hline 2 & $8(3.56 \%)$ & $4(6.45 \%)$ & $4(2.45 \%)$ & & $4(2.45 \%)$ & $1(1.96 \%)$ & $3(2.68 \%)$ & \\
\hline $3+$ & $9(4.00 \%)$ & $4(6.45 \%)$ & $5(3.07 \%)$ & & $5(3.07 \%)$ & $2(3.92 \%)$ & $3(2.68 \%)$ & \\
\hline Total yes & $34(15.1 \%)$ & $15(24.2 \%)$ & $19(11.7 \%)$ & & $19(11.7 \%)$ & $7(13.7 \%)$ & $12(10.7 \%)$ & \\
\hline Platelet tx $48 \mathrm{~h}$ after NEC & $n=225$ & $n=63$ & $n=162$ & & $n=162$ & $n=47$ & $n=115$ & \\
\hline Platelet tx $48 \mathrm{~h}$ after NEC & & & & 0.99 & & & & $<0.001$ \\
\hline 0 & $148(65.8 \%)$ & $42(66.7 \%)$ & $106(65.4 \%)$ & & $106(65.4 \%)$ & $43(91.5 \%)$ & $63(54.8 \%)$ & \\
\hline 1 & $46(20.4 \%)$ & $13(20.6 \%)$ & $33(20.4 \%)$ & & $33(20.4 \%)$ & $3(6.38 \%)$ & $30(26.1 \%)$ & \\
\hline 2 & $17(7.56 \%)$ & $4(6.35 \%)$ & $13(8.02 \%)$ & & $13(8.02 \%)$ & $1(2.13 \%)$ & $12(10.4 \%)$ & \\
\hline $3+$ & $14(6.22 \%)$ & $4(6.35 \%)$ & $10(6.17 \%)$ & & $10(6.17 \%)$ & $0(0.00 \%)$ & $10(8.70 \%)$ & \\
\hline Total yes & $77(34.2 \%)$ & $21(33.3 \%)$ & $56(34.6 \%)$ & & $56(34.6 \%)$ & $4(8.51 \%)$ & $52(45.2 \%)$ & \\
\hline Blood tx before NEC & $n=282$ & $n=73$ & $n=209$ & & $n=209$ & $n=100$ & $n=109$ & \\
\hline Blood tx before NEC & & & & 0.823 & & & & 0.036 \\
\hline 0 & $147(52.1 \%)$ & $35(47.9 \%)$ & $112(53.6 \%)$ & & $112(53.6 \%)$ & $56(56.0 \%)$ & $56(51.4 \%)$ & \\
\hline 1 & $27(9.57 \%)$ & $8(11.0 \%)$ & $19(9.09 \%)$ & & $19(9.09 \%)$ & $9(9.00 \%)$ & $10(9.17 \%)$ & \\
\hline 2 & $32(11.3 \%)$ & $8(11.0 \%)$ & $24(11.5 \%)$ & & $24(11.5 \%)$ & $5(5.00 \%)$ & $19(17.4 \%)$ & \\
\hline $3+$ & $76(27.0 \%)$ & $22(30.1 \%)$ & $54(25.8 \%)$ & & $54(25.8 \%)$ & $30(30.0 \%)$ & $24(22.0 \%)$ & \\
\hline Total yes & $135(47.9 \%)$ & $38(52.1 \%)$ & $97(46.4 \%)$ & & $97(46.4 \%)$ & $44(44.0 \%)$ & $53(48.6 \%)$ & \\
\hline Blood tx before NEC & $n=267$ & $n=73$ & $n=194$ & & $n=194$ & $n=91$ & $n=103$ & \\
\hline Blood tx $48 \mathrm{~h}$ after NEC & & & & 0.003 & & & & $<0.001$ \\
\hline 0 & $108(40.4 \%)$ & $17(23.3 \%)$ & $91(46.9 \%)$ & & $91(46.9 \%)$ & $66(72.5 \%)$ & $25(24.3 \%)$ & \\
\hline 1 & $89(33.3 \%)$ & $28(38.4 \%)$ & $61(31.4 \%)$ & & $61(31.4 \%)$ & $22(24.2 \%)$ & $39(37.9 \%)$ & \\
\hline 2 & $37(13.9 \%)$ & $16(21.9 \%)$ & $21(10.8 \%)$ & & $21(10.8 \%)$ & $2(2.20 \%)$ & $19(18.4 \%)$ & \\
\hline $3+$ & $33(12.4 \%)$ & $12(16.4 \%)$ & $21(10.8 \%)$ & & $21(10.8 \%)$ & $1(1.10 \%)$ & $20(19.4 \%)$ & \\
\hline Total yes & $159(59.6 \%)$ & $56(76.7 \%)$ & $103(53.1 \%)$ & & $103(53.1 \%)$ & $25(27.5 \%)$ & $78(75.7 \%)$ & \\
\hline
\end{tabular}

Cells are represented as $n(\%)$, differences in categorical measures were tested using a chi-square test or Fisher's exact test.

$M N F$ medical non-fulminant NEC, $S N F$ surgical non-fulminant NEC.

Acknowledgements We would like to thank Dr Robert Christensen (Professor and Division Chief of Neonatology at Intermountain Medical Center, Utah), Dr Akhil Maheshwari (Professor, Department of Pediatrics/Neonatology at John Hopkins Hospital, Baltimore), and Dr Martha C. Sola-Visner (Department of Neonatology, Boston Children Hospital, and Boston, Massachusetts) for critically reviewing the manuscript and providing for all the feedback and guidance.

Author contributions PMG designed the study. PMG, VO, AC, BV, HH, HM, JLP, MAYA, CDJ collected and analyzed the data. PMG, MAYA wrote the manuscript. All the authors contributed to and approved the manuscript.

\section{Compliance with ethical standards}

Conflict of interest The authors declare no competing interests.
Publisher's note Springer Nature remains neutral with regard to jurisdictional claims in published maps and institutional affiliations.

\section{References}

1. Neu J, Walker WA. Necrotizing enterocolitis. N Engl J Med. 2011;364:255-64.

2. Sankaran K, Puckett B, Lee DS, Seshia M, Boulton J, Qiu Z, et al. Variations in incidence of necrotizing enterocolitis in Canadian neonatal intensive care units. J Pediatr Gastroenterol Nutr. 2004; 39:366-72.

3. Sjoberg Bexelius T, Ahle M, Elfvin A, Bjorling O, Ludvigsson JF, Andersson RE. Intestinal failure after necrotising enterocolitis: incidence and risk factors in a Swedish population-based longitudinal study. BMJ Paediatrics Open. 2018;2:e000316.

4. Allin BSR, Long AM, Gupta A, Lakhoo K, Knight M. One-year outcomes following surgery for necrotising enterocolitis: a UK- 
wide cohort study. Arch Dis Child Fetal Neonatal Ed. 2018;103: F461-6.

5. Knell J, Han SM, Jaksic T, Modi BP. Current status of necrotizing enterocolitis. Curr Probl Surg. 2019;56:11-38.

6. Stoll BJ, Hansen NI, Bell EF, Walsh MC, Carlo WA, Shankaran S, et al. Trends in care practices, morbidity, and mortality of extremely preterm neonates, 1993-2012. JAMA. 2015;314:1039-1051.

7. Santulli TV, Schullinger JN, Heird WC, Gongaware RD, Wigger J, Barlow B, et al. Acute necrotizing enterocolitis in infancy: a review of 64 cases. Pediatrics. 1975;55:376-87.

8. Mowitz ME, Dukhovny D, Zupancic JAF. The cost of necrotizing enterocolitis in premature infants. Semin fetal Neonatal Med. 2018;23:416-9.

9. Ganapathy V, Hay JW, Kim JH, Lee ML, Rechtman DJ. Long term healthcare costs of infants who survived neonatal necrotizing enterocolitis: a retrospective longitudinal study among infants enrolled in Texas Medicaid. BMC Pediatr. 2013;13:127.

10. Kurscheid T, Holschneider AM. Necrotizing enterocolitis (NEC)mortality and long-term results. Eur J Pediatr Surg. 1993;3:139-43.

11. Thakkar HS, Lakhoo K. The surgical management of necrotising enterocolitis (NEC). Early Hum Dev. 2016;97:25-8.

12. Raval MV, Moss RL. Current concepts in the surgical approach to necrotizing enterocolitis. Pathophysiol: Off J Int Soc Pathophysiol. 2014;21:105-10.

13. Rees CM, Hall NJ, Eaton S, Pierro A. Surgical strategies for necrotising enterocolitis: a survey of practice in the United Kingdom. Arch Dis Child Fetal Neonatal Ed. 2005;90:F152-5.

14. Maheshwari A. Immunologic and hematological abnormalities in necrotizing enterocolitis. Clin Perinatol. 2015;42:567-85.

15. Hutter JJ Jr., Hathaway WE, Wayne ER. Hematologic abnormalities in severe neonatal necrotizing enterocolitis. J Pediatr. 1976; 88:1026-31.

16. Ragazzi S, Pierro A, Peters M, Fasoli L, Eaton S. Early full blood count and severity of disease in neonates with necrotizing enterocolitis. Pediatr Surg Int. 2003;19:376-9.

17. Patel CC. Hematologic abnormalities in acute necrotizing enterocolitis. Pediatr Clin North Am. 1977;24:579-84.

18. Kenton AB, O'Donovan D, Cass DL, Helmrath MA, Smith EO, Fernandes CJ, et al. Severe thrombocytopenia predicts outcome in neonates with necrotizing enterocolitis. J Perinatol. 2005;25:14-20.

19. Ververidis M, Kiely EM, Spitz L, Drake DP, Eaton S, Pierro A. The clinical significance of thrombocytopenia in neonates with necrotizing enterocolitis. J Pediatr Surg. 2001;36:799-803.

20. Lambert DK, Christensen RD, Baer VL, Henry E, Gordon PV, Besner GE, et al. Fulminant necrotizing enterocolitis in a multihospital healthcare system. J Perinatol. 2012;32:194-8.

21. MohanKumar K, Namachivayam K, Song T, Jake Cha B, Slate A, Hendrickson JE, et al. A murine neonatal model of necrotizing enterocolitis caused by anemia and red blood cell transfusions. Nat Commun. 2019;10:3494.

22. Patel RM, Knezevic A, Shenvi N, Hinkes M, Keene S, Roback JD, et al. Association of red blood cell transfusion, anemia, and necrotizing enterocolitis in very low-birth-weight infants. JAMA. 2016;315:889-97.

23. Garg P, Pinotti R, Lal CV, Salas AA. Transfusion-associated necrotizing enterocolitis in preterm infants: an updated metaanalysis of observational data. J Perinat Med. 2018;46:677-85.

24. Garg PM, Ravisankar S, Bian H, Macgilvray S, Shekhawat PS. Relationship between packed red blood cell transfusion and severe form of necrotizing enterocolitis: a case control study. Indian Pediatr. 2015;52:1041-5.

25. Cremer M, Sola-Visner M, Roll S, Josephson CD, Yilmaz Z, Bührer $\mathrm{C}$, et al. Platelet transfusions in neonates: practices in the United States vary significantly from those in Austria, Germany, and Switzerland. Transfusion. 2011;51:2634-41.

26. Patel RM, Josephson CD, Shenvi N, Maheshwari A, Easley KA, Stowell S, et al. Platelet transfusions and mortality in necrotizing enterocolitis. Transfusion. 2019;59:981-8.

27. Kenton AB, Hegemier S, Smith EO, O'Donovan DJ, Brandt ML, Cass DL, et al. Platelet transfusions in infants with necrotizing enterocolitis do not lower mortality but may increase morbidity. $\mathbf{J}$ Perinatol. 2005;25:173-7.

28. Curley A, Stanworth SJ, Willoughby K, Fustolo-Gunnink SF, Venkatesh V, Hudson C, et al. Randomized trial of platelettransfusion thresholds in neonates. N Engl J Med. 2019;380: $242-51$.

29. Lin L, Xia X, Liu W, Wang Y, Hua Z. Clinical characteristics of neonatal fulminant necrotizing enterocolitis in a tertiary Children's hospital in the last 10 years. PLoS ONE. 2019;14:e0224880.

30. Hyman PE, Abrams CE, Zipser RD. Enhanced urinary immunoreactive thromboxane in neonatal necrotizing enterocolitis. A diagnostic indicator of thrombotic activity. Am J Dis Child. 1987;141:686-9.

31. Hsueh W, Caplan MS, Qu XW, Tan XD, De Plaen IG, GonzalezCrussi F. Neonatal necrotizing enterocolitis: clinical considerations and pathogenetic concepts. Pediatr Dev Pathol. 2003;6:6-23.

32. Namachivayam K, MohanKumar K, Shores DR, Jain SK, Fundora $\mathrm{J}$, Everett AD, et al. Targeted inhibition of thrombin attenuates murine neonatal necrotizing enterocolitis. Proc Natl Acad Sci U S A. 2020;117:10958-69.

33. Namachivayam K, MohanKumar K, Garg L, Torres BA, Maheshwari A. Neonatal mice with necrotizing enterocolitis-like injury develop thrombocytopenia despite increased megakaryopoiesis. Pediatr Res. 2017;81:817-24.

34. Cremer M, Weimann A, Szekessy D, Hammer H, Bührer C, Dame C. Low immature platelet fraction suggests decreased megakaryopoiesis in neonates with sepsis or necrotizing enterocolitis. J Perinatol. 2013;33:622-6.

35. Cekmez F, Tanju IA, Canpolat FE, Aydinoz S, Aydemir G, Karademir F, et al. Mean platelet volume in very preterm infants: a predictor of morbidities? Eur Rev Med Pharm Sci. 2013;17: 134-7.

36. Desiraju S, Bensadoun J, Bateman D, Kashyap S. The role of absolute monocyte counts in predicting severity of necrotizing enterocolitis. J Perinatol. 2020;40:922-7.

37. MohanKumar K, Kaza N, Jagadeeswaran R, Garzon SA, Bansal A, Kurundkar AR, et al. Gut mucosal injury in neonates is marked by macrophage infiltration in contrast to pleomorphic infiltrates in adult: evidence from an animal model. Am J Physiol Gastrointest Liver Physiol. 2012;303:G93-102.

38. Remon J, Kampanatkosol R, Kaul RR, Muraskas JK, Christensen $\mathrm{RD}$, Maheshwari A. Acute drop in blood monocyte count differentiates NEC from other causes of feeding intolerance. J Perinatol. 2014;34:549-54

39. Wang YC, Chan OW, Chiang MC, Yang PH, Chu SM, Hsu JF, et al. Red blood cell transfusion and clinical outcomes in extremely low birth weight preterm infants. Pediatr Neonatol. 2017;58: 216-22. 